\title{
Perkembangan Sejarah dan Isu-Isu Terkini dalam Sastra Bandingan
}

\author{
The Historical Development and Current Issues in Comparative Literature
}

\author{
Dipa Nugraha \\ Universitas Muhammadiyah Surakarta \\ Corresponding email: dipa.nugraha@ums.ac.id
}

Received: 31 October 2020 Accepted: 24 February 2021 Published: 1 June 2021

\begin{abstract}
This article aims to describe the historical development of comparative literature and its current issues. Comparative literature is a mandatory course in the Indonesian language and literature study program in most Indonesian universities. There are at least six books used as common references in teaching comparative literature in Indonesia. However, these books have not covered recent development in comparative literature, especially the emergence of Chinese school and some new directions within comparative literature. This literature review article collects references from selective authoritative sources on the internet to describe the historical development of comparative literature and its current issues. This article shows that the expansions in comparative literature are intricate with deconstruction and reconstruction of world literature, dialogue and the meeting between West and East, and the presence of the digital age. From the dialogue on world literature and West meeting East vice versa, the Chinese school has its foundation, whilst the presence of the digital age makes comparative literature have new things to explore and work on the usage of the different medium in an umbrella term, intermediality.
\end{abstract}

Keywords: comparative literature, world literature, Chinese school, digital era, intermediality.

\begin{abstract}
Abstrak: Artikel ini bertujuan membahas perkembangan sejarah dan isu-isu terkini sastra bandingan. Sastra bandingan atau comparative literature hadir sebagai mata kuliah wajib di program studi bahasa dan sastra Indonesia dengan nama Sastra Bandingan atau Ilmu Perbandingan Sastra di sebagian besar universitas di Indonesia. Dari enam buku rujukan berbahasa Indonesia yang sering dipergunakan di dalam pengajaran sastra bandingan terdapat gap terkait dengan belum begitu dibahasnya perkembangan mazhab Cina dan adanya arah baru di dalam sastra bandingan. Artikel ulasan pustaka ini menggunakan metode pencarian data dunia maya dalam rangka mengumpulkan rujukan-rujukan dari sumber otoritatif pilihan yang dapat menghasilkan suatu tulisan sintesis mengenai sejarah dan isu-isu terkini dalam sastra bandingan. Hasil penelitian menunjukkan bahwa perluasan lingkup kajian di dalam sastra bandingan diwarnai dengan wacana dekonstruksi dan rekonstruksi sastra dunia, dialog dan pertemuan antara Barat dan Timur, serta isu yang terkait dengan era digital. Dari isu tentang sastra dunia dan pertemuan Barat dan Timur, mazhab Cina menemukan jalan lahirnya sedangkan kehadiran era digital membuat sastra bandingan merambah pada ranah baru pada istilah yang memayungi beberapa isu mengenai penggunaan media yang berbeda, yaitu intermedialitas.
\end{abstract}

Kata kunci: sastra bandingan, sastra dunia, mazhab Cina, era digital, intermedialitas.

To cite this article:

Nugraha, D. (2021). Perkembangan Sejarah dan Isu-Isu Terkini dalam Sastra Bandingan. Diglosia: Jurnal Kajian Bahasa, Sastra, dan Pengajarannya, 4(2), 163-176. https://doi.org/10.30872/diglosia.v4i2.135 


\section{A. PENDAHULUAN}

Saat globalisasi membuat dunia semakin tanpa batas serta kebutuhan memahami bangsa dan kebudayaan lain di dalam membangun interaksi dan komunikasi lintas budaya kian menguat, sastra bandingan menjadi penting di dalam membantu mengenal dan memahami kebudayaan bangsa lain (Hart, 2006, p. 20) dalam suasana multikulturalisme dan mengemukanya perlawanan terhadap homogenisasi kultural dari dominasi kebudayaan tertentu dalam kajian sastra dan budaya (Bernheimer, 1995; Saussy, 2006; Zamora, 2004). Sastra bandingan atau comparative literature adalah ilmu yang mengkaji karya sastra dan segala jenis ekspresi atau produk budaya yang melintasi batas linguistik dan atau latar belakang budaya. Menimbang peran dan manfaat sastra bandingan, tidaklah aneh jika kemudian membuatnya menjadi mata kuliah wajib dengan nama Sastra Bandingan (atau Ilmu Perbandingan Sastra) di beberapa program studi yang mengajarkan bahasa dan sastra di Indonesia.

Terdapat setidaknya enam buku berbahasa Indonesia yang lazim digunakan sebagai rujukan dalam pengajaran mata kuliah Sastra Bandingan di Indonesia. Bukubuku tersebut adalah Teori Kesusastraan (1993) yang merupakan terjemah dari buku karya René Wellek dan Austin Warren dengan judul Theory of Literature, buku karya Andries Teeuw yang berjudul Sastra dan Ilmu Sastra: Pengantar Teori Sastra (1984) pada bagian X-XI, dua buku karya Endraswara Metodologi Penelitian Sastra (2013) dan Metodologi Penelitian Sastra Bandingan (2011), serta dua buku karya Sapardi Djoko Damono yang berjudul Pegangan Penelitian Sastra Bandingan (2005) dan Sastra Bandingan (2009). Dari buku-buku berbahasa Indonesia yang terkait dengan sastra bandingan ini, belum ada pembahasan berkenaan dengan perkembangan terbaru di dalam sastra bandingan yang menghadirkan eksistensi mazhab Cina dan isu-isu baru di dalam sastra bandingan. Kontribusi yang diharapkan dari artikel ini adalah mengisi gap yang ada di dalam literatur pembelajaran sastra bandingan yang terdapati di beberapa buku yang telah terbit di Indonesia serta memberikan rujukan tambahan bagi pembelajaran dan praktik sastra bandingan.

\section{B. METODE}

Artikel ini adalah artikel ulasan pustaka (literature review article). Artikel ulasan pustaka bertujuan memberikan deskripsi perkembangan terbaru berkaitan dengan suatu hal yang spesifik yang dapat memberikan perspektif baru, menyuguhkan gap penelitian atau pendapat yang sudah ada, atau sebagai rujukan untuk peneliti berikutnya (Bolderston, 2008; Wee \& Banister, 2016) dan bukan sekadar mengumpulkan pustaka yang ada dan relevan dengan topik yang dibicarakan (Aaron, 2008, p. 185). Oleh karenanya, artikel ini memberikan hal-hal tersebut yang terkait dengan sastra bandingan.

Melalui praktik 5C atau cite, compare, contrast, critique, connect the literature (Andersson, Beveridge, \& Singh, 2007, p. 2; Jesson \& Lacey, 2006, p. 140), artikel ulasan pustaka menggunakan segala dokumen dan informasi yang telah ada dan tersedia justru untuk menunjukkan adanya sejumlah perbedaan pendapat dan pandangan sehingga pembandingan dari perbedaan yang ada dapat memberikan sebuah rangkuman dari perkembangan terbaru dan kemungkinan sintesis darinya. Di dalam konteks artikel ini, dokumen dan informasi yang ada adalah segala macam buku dan artikel dari sumber otoritatif pilihan yang relevan dengan tema kajian. 
Metode yang dipergunakan di dalam penyusunan artikel ini merupakan adaptasi dari paparan Aaron (2008, pp. 185-186) tentang metode di dalam penyusunan artikel ulasan pustaka. Sementara Aaron (2008) melakukan pengumpulan pustaka rujukan di perpustakaan tertentu atau menggunakan pangkalan data tertentu, penulis artikel ini melakukan pencarian dengan menggunakan mesin pencari Google untuk mencari artikel-artikel yang relevan dan dibutuhkan. Berbagai buku atau artikel berkenaan dengan sejarah, perkembangan, dan isu-isu terbaru sastra bandingan dibaca untuk diekstrak, dibandingkan, disintesis.

\section{PEMBAHASAN}

\section{Sejarah Awal Sastra Bandingan}

Kerja perbandingan karya sastra pertama kali dapat ditarik jauh mundur pada Palladis Tamia: Wits Treasury (1598) karya Francis Meres. Meres, seorang pengkaji sastra dari Inggris, membandingkan perbandingan wacana di dalam sajak-sajak karya penyair Inggris dengan sajak-sajak dari para penyair Yunani, Latin, dan Italia (Şahin, 2015, p. 6). Namun sastra bandingan sebagai sebuah disiplin akademis menurut Weisstein (1984, p. 169) dianggap baru mulai berkembang dari Perancis melalui terbitnya jurnal Revue de Littérature Comparée pada tahun 1921 di bawah asuhan Fernand Baldensperger atau terbitnya karya Paul Van Tieghem yang berjudul La Littérature Comparée pada tahun 1931.

Pendapat lain diajukan Franco (2018, pp. 66-67) yang menyebut bahwa perjalanan sastra bandingan dapat dikatakan dimulai dari François Noël and Guislain de Laplace yang menerbitkan Cours de Littérature Comparée pada tahun 1804. Kemudian ada nama Abel-François Villemain yang di tahun 1820an memberikan seri kuliah mengenai perbandingan sastra dan materi kuliahnya ini diterbitkan pada tahun 1828, 1829, dan 1830 yang membahas sastra abad ke-18 dan pembandingan karya sastra di abad pertengahan yang berasal dari Perancis, Italia, Spanyol, dan Inggris. Nama lain yang dianggap sebagai peneroka sastra bandingan adalah JeanJacques Ampère. Pada tahun 1830 Jean-Jacques Ampère memberikan presentasi di Athénée de Marseille mengenai perbandingan sejarah seni dan sastra antarbangsa. Di dalam presentasinya, ia menyinggung adanya dua cabang di dalam studi sastra: teori sastra dan sejarah sastra. Di dalam sejarah sastra, metodologi yang diterapkan adalah melalui perbandingan dan filiasi. Di dalam perbandingan, metode yang dipakai adalah fokus pada pararelisme dan kontras sedangkan pada filiasi akan didapati keterkaitan karya sastra berdasarkan pada kapan satu karya lahir mendahului karya lainnya di dalam perbandingan (Boldor, 2003, pp. 29-30; Claudon, 2018; D’haen, 2013, pp. 51-52; Domínguez, Saussy, \& Villanueva, 2014). Pembicaraan sastra bandingan oleh akademisi-akademisi Perancis dianggap sebagai tonggak kelahiran sastra bandingan sebagai sebuah disiplin di dunia akademik sehingga tidaklah mengherankan jika kemudian Perancis disebut sebagai negeri awal mula sastra bandingan.

Di Inggris, sastra bandingan hadir ketika Matthew Arnold memperkenalkan istilah comparative literatures dalam bentuk jamak pada tahun 1857 di dalam sebuah ceramah yang ia berikan di Universitas Oxford saat inaugurasi dirinya sebagai profesor di bidang sajak sebagai terjemah dari istilah littérature comparée atau histoire comparative berkat pengaruh akademisi Perancis. Di dalam ceramah ini, ia menyatakan bahwa "no single event, no single literature is adequately comprehended except in relation to other events, to other literatures (tidak ada sebuah kejadian, tidak ada sebuah 
karya sastra yang cukup dipahami kecuali dengan keterkaitannya atas kejadiankejadian lainnya, terhadap karya-karya sastra lainnya)." Istilah comparative literature bahkan tercatat sudah ia pergunakan jauh sebelumnya seperti tercantum di dalam sebuah surat yang tidak dipublikasikan yang ditulis pada tahun 1848 sebagai terjemah dari istilah histoire comparative (Brown, 2013, p. 68; Jay, 2014; Şahin, 2015, p. 6). Menurut Anderson (1971), nilai penting mulai diperkenalkan istilah comparative literature oleh Matthew Arnold bukan hanya karena disiplin ini menyeberang dari Eropa daratan ke tanah Inggris atau bagaimana istilah Perancis kemudian diterjemahkan ke dalam bahasa Inggris oleh seorang penulis Inggris namun terletak pada kerja pembandingan yang mengarah kepada kontras. Masih di dalam konsep Arnold, saat bicara tentang karya-karya sastra Yunani dan Kristen di abad pertengahan seharusnya bukan dalam lingkup yang saling terisolasi antara satu dengan lainnya sebab karya-karya yang ada tidak akan dapat dipahami dengan baik tanpa saling membandingkannya. Ia menyaran kepada praktik yang lebih spesifik lagi bahwa kerja sastra bandingan adalah membandingkan karya-karya klasik dengan karya yang tercipta di masa kini dan lahir di tanah Inggris untuk memahami bagaimana perspektif bangsa lain dibandingkan dengan bangsa Inggris.

Di dalam proses pembandingan, Arnold menyatakan adanya kerja yang mencakup aktivitas pembandingan, pembedaan, penolakan, dan pemilihan preferensi. Arnold dapat dikatakan memiliki kontribusi terhadap perkembangan disiplin ilmu sastra bandingan dan lebih mempopulerkan sastra bandingan meskipun ia bukan seorang peneroka.

Sastra bandingan memiliki latar belakang pada tradisi kritik romantik di dalam perdebatan mengenai universalitas konsep keindahan, bentuk-bentuk seni, dan pertautannya dengan beraneka rupa peradaban yang ada (lih. Franco, 2018, pp. 6566), munculnya persaingan masalah keunggulan antarbangsa bersamaan dengan kelahiran pembicaraan mengenai negara bangsa di Eropa di awal abad ke-19 saat, dan kelahiran nasionalisme dengan pernik yang terkait dengan konstruk sejarah sastra yang terikat pada kebangsaan (Beecroft, 2013, pp. 2-3). Arnold memotret bagaimana suasana persaingan keunggulan antarbangsa Eropa saat itu dengan pernyataan semisal: "kritikus di Inggris harus mengetahui sastra di luar Inggris dan harus memadankan diri dengan standar Eropa" (Boldor, 2003, pp. 33-34) atau "untuk mengetahui bagaimana bangsa lain [di Eropa] berpijak, sehingga kita juga tahu bagaimana diri kita berpijak [dalam masalah kesusastraan]" (Anderson, 1971, p. 290). Oleh sebab itulah, konsep sastra dunia atau world literature juga seharusnya dilihat dalam konteks suasana di Eropa di masa itu (Beecroft, 2013). Waktu itu batasbatas negara bangsa modern di Eropa mulai menjadi perhatian serius dan pembagian karya sastra berdasarkan negara bangsa menjadi bagian yang seharusnya tidak terpisahkan di dalam konstruk wacananya.

Dalam situasi persaingan antarnegara dalam masalah sastra inilah, sastra bandingan saat itu menjadi ajang "pengunjukan bakat nasional sembari menempatkan beberapa pengarang dari negara lain sebagai sastrawan yang berada pada tingkat di bawahnya" dan bukan sekadar sebagai kajian pemetaan sastra nasional sebagai bagian dari sastra dunia (Lefevere, 1995, p. 2). Praktik ini berlaku dalam konteks persaingan sastra di Eropa Barat. Namun ketika kemudian sastra bandingan merambah pada karya sastra dari luar Eropa Barat, sastra bandingan mau tidak mau berhadapan dengan tradisi linguistik dan poetika yang sangat jauh berbeda sehingga membuat sastra bandingan tidak bisa menghindar dari kajian 
penerjemahan. Situasi makin mendekatkan sastra bandingan kepada kajian penerjemahan manakala pada awal abad kedua puluh, secara terpisah dan berlatar belakang tradisi sastra yang berbeda, Walter Benjamin dan Ezra Pound menyatakan bahwa praktik penerjemahan karya sastra ke dalam bahasa lain memberikan kehidupan yang baru kepada sebuah karya sastra selain dapat membantu perkembangan atau memberikan pengaruh terhadap bahasa, sastra, dan budaya suatu bangsa. Pandangan ini kemudian turut memberikan status baru kepada penerjemah sebab penerjemahlah yang memberikan nyawa baru kepada karya yang ia terjemahkan serta menjadi penentu model nyawa yang seperti apa bakal diberikan kepada terjemahan yang akan ia ciptakan dengan pertimbangan-pertimbangan semisal target pembaca dan kesesuaian dengan konteks zaman (Lefevere, 1995, pp. 6-7). Dari sinilah kemudian kajian penerjemahan tidak berkutat hanya pada masalah presisi terjemahan dan perbedaan yang ada di antara terjemahan-terjemahan atas sebuah teks.

Kajian penerjemahan kembali menemukan situasi baru di hadapan sastra bandingan pada tahun 70an dan 80an dengan perkembangan teori resepsi sastra yang menekankan pada keberterimaan sebuah karya oleh pembaca dan dekonstruksi yang menekankan pada destinasi teks. Berdasarkan konsep resepsi sastra, keberterimaan dan citra sebuah karya pada karya terjemahan terletak di tangan penerjemah. Penerjemah menjadi figur penting, bahkan bisa dikatakan lebih penting, daripada pencipta asli sebuah karya. Di dalam pandangan gerakan dekonstruksi, karya terjemahan juga mendapatkan sandarannya. Karya terjemahan adalah justru karya yang sampai di hadapan pembacanya meskipun sebenarnya adalah transformasi dari yang original sedangkan karya original tidak pernah menemukan destinasinya (Lefevere, 1995, pp. 8-9). Berdasarkan dinamika yang ada atas sastra bandingan seperti baru saja dipaparkan, penerjemahan kemudian mulai menjadi salah satu wilayah kajian dalam sastra bandingan.

Masuknya penerjemahan sebagai wilayah yang juga digarap di dalam sastra bandingan diyakini oleh Bermann (2009) sebagai sebuah keniscayaan ketika interaksi dan pemahaman antarkebudayaan di era globalisasi menjadi kian menguat. Di dalam artikelnya terkait dengan sastra bandingan dan kajian penerjemahan, Bermann (2009, pp. 438-442) menunjukkan bahwa kajian penerjemahan di dalam sastra bandingan dapat dilihat sebagai manifestasi dari tiga hal, yaitu: 1 . Terjemahan sebagai sebuah teks yang kompleks sebab melibatkan tidak hanya pemindahan dari satu bahasa ke bahasa lainnya tetapi juga kompleksitas lintas disiplin yang mungkin terlibat di dalam proses penerjemahan dan diskursus yang terlibat di dalam prosesnya dari teks original, 2. Penerjemahan sebagai sebuah proses yang tidak pernah selesai sebab bagaimanapun juga tidak pernah ada terjemahan yang sempurna. Di dalamnya selalu melibatkan ekspansi dan transformasi kata-kata dan makna dari teks original sehingga melahirkan multiplisitas teks, 3. Kajian penerjemahan dan sastra bandingan sebagai dua displin ilmu yang berbeda dapat saling berkolaborasi di dalam penggarapan isu-isu yang terkait dengan penerjemahan di dalam sastra bandingan.

\section{Apa yang Dibandingkan dalam Sastra Bandingan?}

Gaither (1961, p. 154) berpendapat bahwa secara umum terdapat tiga pendekatan di dalam sastra bandingan, yaitu kajian keterkaitan antara bentuk dan isi, kajian pengaruh, dan kajian sintesis karya. Sementara itu, Brown (2013) mencatat beberapa perbedaan pendapat tentang sastra bandingan mulai dari perbedaan 
tentang karya sastra yang seperti apa dan dari mana yang harus dibandingkan (kanon dan klasik Eropa dengan karya Eropa lainnya, kanon Eropa dengan karya di luar Eropa, atau lebih luas dari itu) hingga batas lingkup sastra bandingan yang seharusnya berkutat pada karya sastra saja atau bisa meluas kepada hasil kebudayaan lainnya. Brown (2013) lantas membuat beberapa catatan penting terkait dengan sastra bandingan di antaranya sebagai berikut. Pertama, sastra bandingan adalah keniscayaan menunjukkan persamaan dan perbedaan. Kedua, proses dan hasil dari pembandingan selalu problematik karena tujuan membandingkan tentu dilakukan dalam rangka mencari perbedaan dan persamaan sehingga luaran yang muncul tentu perbedaan dan persamaan. Pernyataan di dalam simpulan terkait dengan persamaan dan perbedaan antarkarya sebenarnya jatuh kepada ranah retorika. Ketiga, sastra bandingan memperhatikan isu yang terkait dengan keterbandingan. Sastra bandingan, meskipun bisa saja membandingkan karya-karya apa saja, tetap mempraktikkan pembandingan karya yang memang pantas dan dianggap memiliki kadar keterkaitan tertentu untuk dibandingkan. Keempat, dalam mengambil karyakarya sebagai objek sastra bandingan, harus dipertimbangkan bagaimana karyakarya yang menjadi objek kajian mampu menghasilkan percakapan satu sama lain dalam satu topik atau lebih yang bernilai di dalam menyingkap karya-karya yang dibandingkan dan atau relevan dengan topik pembicaraan.

Pada kajian folklor (folklore studies), kajian sastra bandingan dapat merujuk kepada struktur cerita (grammar of narrative) dan fungsi naratif (narrative functions) yang diperkenalkan oleh Vladimir Propp melalui bukunya yang terbit pertama kali pada tahun 1928, Morphology of the Folktale (1968). Di dalam kajian folklor Proppian, folklore dibandingkan struktur ceritanya dan pola perkembangan ceritanya melalui fungsi aksi dari karakter yang ada di dalamnya. Praktik sastra bandingan dalam kajian folklor lainnya adalah dengan metode geografis-historis (Honko, 1986). Di dalam metode ini, seorang komparatis folklor akan membaca dan membandingkan cerita yang ada untuk melihat interpolasi antarcerita dan bagaimana ketergantungan antarcerita dapat menyingkap keterkaitan dengan dugaan bentuk dan dari wilayah mana cerita kemungkinan berasal. Dalam konteks yang lebih luas, kajian folklor dapat dipergunakan untuk memetakan kemungkinan kekerabatan budaya, distribusi struktur simbol dan makna, identifikasi pengaruh lingkungan dan ekologi terhadap variasi yang muncul, serta hirarki pengaruh satu kebudayaan kepada kebudayaan yang lain.

\section{Dinamika dalam Perkembangan Sastra Bandingan}

Pada tahun 1958, René Wellek mengkritik sastra bandingan karena belum juga menghasilkan metodologi yang jelas di dalam praktiknya. Dengan ketiadaan metodologi spesifik, sastra bandingan menjadi sebuah studi yang mengait-kaitkan fragmen-fragmen yang tidak berkaitan di dalam jejaring keterkaitan yang bisa dengan mudah dipecah dari keutuhan makna. Sastra bandingan mazhab Perancis selama ini dianggap René Wellek hanya mengakumulasikan sejumlah pararelisme, persamaan, dan terkadang identitas di dalam karya sastra yang dibandingkan namun tidak pernah bisa menjelaskan makna dari keterkaitan ini kecuali kemungkinan adanya fakta bahwa penulis terkemudian membaca tulisan penulis sebelumnya. Ia mengkritisi bahwa kajian sastra seharusnya bukan hanya pengakumulasian sumber dan pengaruh di dalam sebuah karya namun tentang bagaimana bahan-bahan mentah dari sumber yang tersedia diasimilasikan ke dalam struktur yang baru. Belum 
lagi masalah yang timbul di dalam memahami keutuhan sebuah karya sastra yang hadir atas dirinya sendiri dengan segala maknanya kemudian dipecah menjadi pembicaraan tentang sumber dan pengaruh (Wellek, 2009, p. 164). Ia menggugat studi sastra bandingan dalam tradisi Eropa yang berorientasi pada kebanggaan nasional dan psikologi suatu bangsa melalui praktik pembandingan karya sastra untuk melacak sumber dan pengaruh sementara melupakan nilai kesusastraan sebuah karya sebagai bentuk dari kesatuan makna yang memiliki dunia dengan situasi khasnya, karakter dan kejadian di dalamnya (Wellek, 2009, pp. 170-171). Gugatan Wellek ini yang menyindir sastra bandingan sebagai kajian sumber dan pengaruh di dalam pemetaan nasionalisme kultural di dalam tradisi Perancis kemudian kepada lahirnya mazhab Amerika yang menekankan pada humanisme universal. Selain René Wellek, nama lain yang terkenal dari mazhab ini adalah Henry H. H. Remak.

Selang beberapa dekade kemudian, kritik terhadap sastra bandingan muncul kembali saat Susan Bassnett melalui bukunya Comparative Literature: A Critical Introduction (1993) menyatakan bahwa sastra bandingan sebagai disiplin ilmu dalam kadar tertentu dapat dikatakan sudah mati (Wang, 2010, p. 28). Meskipun demikian, Bassnett (1993, p. 47) juga menyatakan bahwa sastra bandingan tidak benar-benar mati sebab sebenarnya ia telah muncul dalam bentuk lain, yaitu pembandingan dan penilaian ulang model kultural Barat dengan model kultural lain, berubah melalui metodologi baru menjadi kajian gender dan budaya, pengkajian transfer interkultural melalui aktivitas penerjemahan. Di dalam tulisannya terkemudian, Bassnett (2007) membahas adanya perkembangan dalam pendekatan sastra bandingan selain pengaruh penerjemahan terhadap pembacaan yakni kajian pengaruh (influence) yang melibatkan pencarian akan afinitas (kemiripan) dan intertekstualitas (keterkaitan antarteks).

Sementara itu di dalam buku berjudul Comparative Literature: Theory, Method, Application (1998), Tötösy de Zepetnek menyoroti perkembangan sastra bandingan. Ia (1998, pp. 15-19) menyatakan bahwa sastra bandingan mulai bergeser kepada kajian budaya. Ini memiliki implikasi pada sastra bandingan sebagai kajian sastra. Peletakan kajian sastra ke dalam konteks kajian budaya telah menyebabkan kajian karya dalam konteks kajian nilai kesastraan menjadi terpinggirkan sebab akhirnya faktor budaya yang kerap menjadi fokus di dalam sastra bandingan.

Di balik deras kritik atas belum jelasnya teori dan metodologi sastra bandingan untuk dapat disebut sebagai sebuah disiplin tersendiri di dalam kajian sastra, Edmond (2016) justru tidak terlalu mempermasalahkannya. Menurutnya kerja pembandingan bukanlah sebuah metode atau bahkan sebuah teknik akademik melainkan sebuah strategi pewacanaan (discursive strategy) di dalam merangkul dan memikirkan kembali keterkaitan antardisiplin. Sastra bandingan tidak seharusnya meributkan diri pada aturan kebakuan di dalam dirinya namun justru pada bagaimana sastra bandingan memiliki pengaruh pada hubungan antardisiplin, menghasilkan temuan-temuan yang berpotensi mengejutkan di dalam melihat manusia dan dunia.

Dinamika dalam sejarah perkembangan sastra bandingan selain melahirkan mazhab baru-seperti terjadi dengan kelahiran mazhab Amerika Serikat yang membedakan diri dengan mazhab Perancis dan kemudian disusul dengan munculnya mazhab Cina pada akhir tahun 1970-an yang berkembang sebagai respons atas Erosentrisme atas dua mazhab terkemuka sebelumnya di dalam sastra 
bandingan (Lin \& Huang, 2015)—-kemudian juga melahirkan perluasan lingkup sastra bandingan. Di dalam pendekatan sastra bandingan puritan, kerja pembandingan terletak pada hubungan (connection) dan pengaruh (influence) yang termanifestasikan dari kontak antara karya sastra satu dengan karya lainnya. Kritik dari Wellek, Bassnett, dan Tötösy de Zepetnek melahirkan pendekatan reformis. Pendekatan reformis mengerjakan sastra bandingan dalam kaitan antara karya sastra dengan area lain yang terkait dengan wilayah pengetahuan dan penciptaan seperti seni, filsafat, sejarah, ilmu sosial, agama, dan segala bentuk ekspresi manusia (Blanariu, 2015, pp. 130-131).

Pembicaraan tentang keterbandingan antarkarya yang dijadikan objek kajian juga menjadi pembicaraan di dalam dinamika sastra bandingan. Pendapat yang menganggap tidak perlu adanya kontak langsung antarkarya objek kajian dalam sastra bandingan mengajukan argumen bahwa persamaan yang ada dari temuan dari karya yang dibandingkan malah menunjukkan adanya eksistensi pengalaman manusia yang sifatnya universal di dalam pengungkapan meskipun diekspresikan melalui tradisi karya dan latar budaya yang berbeda. Sementara itu, pendapat yang lain justru menekankan perlunya kontak langsung sebagai latar dari kerja pembandingan karya di dalam sastra bandingan.

Adapun akademisi Cina yang melibatkan diri dalam pembicaraan sastra bandingan, bukan dalam rangka mengunyah-unyah sesuatu yang sebelumnya sudah ada di dalam mazhab Perancis dan Amerika. Tersebutlah misal nama Shunqing Cao yang memberikan pemetaan yang lebih jelas antara mazhab yang sudah ada dengan mazhab Cina. Bidang kajian di dalam sastra bandingan menurut Shunqing Cao (2007, pp. 39-41) dapat terjadi dalam cakupan: (1) kajian lintas negara, (2) kajian lintas bahasa, (3) kajian lintas disiplin, dan (4) kajian lintas peradaban. Perkembangan baru di dalam sastra bandingan ini menurut Cao adalah sesuatu yang wajar di dalam disiplin sastra bandingan. Akademisi Perancis sebagai peletak dasar disiplin sastra bandingan memulai dari konteks saat isu tentang lintas bangsa dan negara hadir di dalam pembicaraan tentang pengaruh dan keterkaitan karya-karya sastra di Eropa. Kajian lintas disiplin menjadi ciri khas mazhab Amerika. Mazhab Amerika memperluas kajian di dalam sastra bandingan dari pembandingan antarkarya sastra kepada pembandingan karya sastra dengan segala bentuk ekspresi manusia atau bersifat lintas disiplin serta mengaitkan pengaruh sebuah karya sastra terhadap ekspresi manusia di negara lain di seluruh dunia. Sementara itu, akademisi Cina mengembangkan sastra bandingan kepada kajian lintas peradaban disebabkan adanya kesadaran konteks yang berubah di dalam dialog antara Barat dan Timur saat meletakkan dan membangun ulang konsep sastra dunia (world literature) yang sebelumnya berporos pada tradisi Erosentris.

Di dalam masalah variasi atas sastra bandingan, Cao (2007, pp. 47-49) juga menjelaskan ada empat variasi di dalam lingkup kerja sastra bandingan, yaitu: (1) variasi pada level linguistik, (2) variasi pada imagologie atau kajian mengenai citra suatu bangsa/negara, (3) kajian variasi kesusastraan dan variasi tesktual yang dapat meliputi themeatologi, genealogi, similaritas dan afinitas, dan (4) kajian variasi budaya atau sistem dan pola kultural. Yang masuk di dalam area kajian ini adalah fenomena penyaringan budaya (cultural filtering). Penyaringan budaya adalah proses dialog dan komunikasi kesusastraan saat penerima akan menyaring pesan-pesan kesusastraan dari sumber melalui pemilahan, penolakan, penciptaan ulang sesuai dengan konteks tradisi dan budaya miliknya. 
Apa yang dipaparkan oleh Cao melengkapi orientasi pembicaraan di dalam pendefinisian istilah sastra bandingan oleh Wellek dan Tötösy de Zepetnek. Wellek (1970 [1942]) memberikan paparan mengenai lingkup kerja sastra bandingan lebih kepada perbedaan pemaknaan akan istilah sastra bandingan. Ia menyebut bahwa istilah sastra bandingan bisa masuk ke dalam tiga bahasan. Pertama, kajian sastra oral yang dapat meliputi hal-hal seperti tema, pola, bentuk cerita folklor, migrasinya, masalah narator dan audience dari cerita folklor, transmisi dan latar sosialnya yang mungkin berkaitan dengan bentuk tulisnya. Kedua, kajian keterkaitan antara satu karya sastra dengan satu karya atau karya-karya lainnya. Di dalam kajian ini, yang menjadi bahasan misalnya adalah masalah pengaruh sebuah karya asing terhadap karya di suatu negara atau bangsa, penerjemahan, faktor-faktor yang menyebabkan suatu karya bisa masuk dan diterima di negara lain, konsep mengenai suatu hal yang dipegang oleh seorang pengarang asing di suatu periode waktu dibandingkan dengan pengarang di suatu negara di periode waktu yang sama atau berbeda. Ketiga, kajian atas sebuah karya sastra dengan segenap totalitasnya yang dibandingkan dengan sastra dunia (world literature).

\section{Gairah Baru dalam Sastra Bandingan: Kelahiran Mazhab Cina}

Saat kelesuan mendera kajian sastra bandingan di Barat, dunia Timur meramaikan disiplin sastra bandingan dengan kehadiran mazhab Cina. Kelahiran mazhab Cina di dalam sastra bandingan menggoyang sastra bandingan dari pengaruh Erosentris. Fusco (2006) melihat kehadiran mazhab Cina di dalam panggung sastra bandingan merupakan hal yang menarik dan pantas dieksporasi dalam usaha Cina masuk di dalam panggung sastra dunia, mendislokasi Erosentrisme, memindahkan teori Barat ke dalam konteks kecinaan, dan menjadi bagian dari langkah akademisi Cina di dalam perebutan panggung pusat sastra dan kebudayaan dunia.

Lin \& Huang (2015) melihat kehadiran mahzab Cina di dalam sastra bandingan dengan sedikit berbeda. Mereka $(2015$, p. 6) tidak berbicara tentang perebutan panggung dan menekankan bahwa kajian sastra dunia di dalam kerja sastra bandingan tidak lain adalah perkara membandingkan sebuah karya dari sebuah budaya yang terproyeksikan oleh liyan di budaya lain. Oleh sebab itu, munculnya sastra bandingan mazhab Cina merupakan penerimaan terhadap keanekaragaman kultural dan pengakuan akan adanya berbagai variasi dialog dan pertukaran di dalam membandingkan dan mengontraskan antara sastra Timur dengan sastra Barat yang justru diperlukan di dalam disiplin sastra bandingan untuk mencari perspektif liyan tidak hanya dalam konteks lintas budaya tetapi juga lintas peradaban.

Hadirnya mazhab Cina dengan tokoh-tokoh seperti Tianhong $\mathrm{Gu}$, Huihua Chen, Kanghua Lu, dan Jingyao Sun justru bakal membuat sastra bandingan tetap eksis dan terus berkembang (Cao, 2007; Lin \& Huang, 2015; Wang, 2010). Wang (2010, pp. 31-32) berargumen bahwa derasnya laju globalisasi serta pengaruh transnasionalisme dan kosmopolitanisme seharusnya secara natural menjadikan sastra bandingan sebagai sebuah disiplin mulai dan tidak bisa menghindari perluasan cakupan istilah sastra dunia (world literature) sebagai sumber bandingan yang sebelumnya berisikan hanya karya sastra besar dari tradisi sastra Barat. Sastra bandingan harus melintasi batas Barat dengan Timur, bukan hanya karya klasik atau kanon Eropa, melintasi batasan dari istilah sastra dunia yang menggunakan Eropa sebagai pusat bandingan karya sastra, melintasi batas antara sastra dengan subjek 
relevan lainnya, bahkan di dalam konteks berkembangnya mazhab Cina di dalam sastra bandingan juga kerja banding lintas batas sastra Cina dengan sastra dari negara Asia lain atau wilayah lainnya.

Lebih lanjut, Jay (2014) melihat adanya ketidakmungkinan untuk menahan perkembangan sastra bandingan kepada praktik sastra bandingan yang bersifat lintas disiplin dan perjalanan teori dari Barat ke Timur [seperti di dalam kelahiran mazhab Cina]. Malah sejatinya ia percaya bahwa hal itu adalah sebuah kebutuhan demi perkembangan sebuah disiplin ilmu. Sastra bandingan harus beroperasi di dalam ruang-ruang lintas disiplin dan menjelajah ruang-ruang antarlokasi, identitas, dan kebangsaan sebagaimana terdapati di dalam kajian-kajian lainnya.

\section{Wilayah Baru dalam Sastra Bandingan}

Tötösy de Zepetnek di dalam bukunya yang berjudul Comparative Literature: Theory, Method, Application (1998) serta dua artikelnya yang berjudul "From Comparative Literature Today toward Comparative Cultural Studies" (1999) dan "About the Situation of the Discipline of Comparative Literature and Neighboring Fields in the Humanities Today" (2017) menggabungkan aspek-aspek di dalam sastra bandingan dengan kajian budaya menjadi suatu pendekatan yang ia beri nama kajian budaya bandingan (comparative cultural studies). Di dalam kajian budaya bandingan, sastra bandingan yang selama ini sudah berlangsung tidak dihilangkan hanya diperluas sebagaimana mazhab Amerika yang mengenal kajian lintas disiplin dengan menggunakan metodologi ke-intradisiplin-an (analisis dan riset lintas disiplin dalam lingkup ilmu humaniora), ke-multidisiplin-an (analisis dan riset lintas disiplin dengan menggunakan sesuatu dari luar ilmu humaniora oleh seorang peneliti), dan kepluridisiplin-an (analisis dan riset yang dilakukan melalui kerja tim dari disiplin ilmu yang berbeda) yang juga merambah pada kajian penerjemahan sebagaimana arah Bassnett, kajian interart (lintas seni), intermedialitas (kajian mengenai penyajian karya dan keterkaitan antarkarya melalui media yang berbeda), dan digitalitas.

Pembicaraan sastra bandingan yang mulai menyinggung kajian intermedialitas juga dilakukan oleh Blanariu (2015). Kajian intermedialitas (Wolf, 2011, p. 2) dilandasi atas kenyataan bahwa media mempengaruhi bagaimana sebuah isi karya dapat dibayangkan untuk diciptakan, bagaimana bakal disajikan, dan bagaimana penikmat karya mempunyai pengalaman yang berbeda. Istilah intermedialitas ini menjadi payung bagi beberapa istilah di dalam kajian karya yang terkait dengan penggunaan, perluasan, dan adaptasi atau penyajian ulang melalui bermacam media seperti multimodalitas, transmedialitas, dan remediasi (Baetens \& Sánchez-Mesa, 2015; Blanariu, 2015; Rajewsky, 2005).

Walaupun tidak menyinggung langsung perluasan sastra bandingan menjadi kajian budaya bandingan ala Tötösy de Zepetnek, Lu (2017) menganggap perluasan sastra bandingan kepada kajian budaya justru akan menghilangkan identitas dari sastra bandingan. Ia mengusulkan perlunya sastra bandingan membuka dirinya di dalam pendefinisian sastra dunia (world literature) dan menghilangkan monolog. Lu tidaklah sendirian di dalam mengkritik sempitnya sastra bandingan jikalau istilah ini hanya merujuk pada sastra kanon yang berpijak awalnya pada paradigma Erosentris (bahkan kepada karya sastra dari Timur yang dianggap bagian dari sastra dunia juga dikanonkan menurut perspektif Erosentris) dan mensubordinasi karya sastra ke dalam ruang. Saussy (2011), misalnya, juga mempermasalahkan penggunaan istilah sastra dunia serta bagaimana konsep universalitas sastra diterapkan di dalam sastra 
bandingan. Sastra bandingan harus menerima sebuah model kesusastraan yang menerima adanya dunia-dunia (worlds) di dalam kemajemukan pengalaman, proyeksi, referensi, dan kerangka rujukan kesusastraan umat manusia.

\section{PENUTUP}

Sastra bandingan yang pada mulanya lahir untuk mengkaji sastra kanon dari Inggris, Jerman, Perancis, Italia, dan Spanyol dalam konteks akar tradisi sastra Eropa, pengaruhnya terhadap sastra satu sama lain, dan pengaruhnya terhadap sastra bangsa-bangsa lainnya di Eropa, di dalam perkembangan selanjutnya mengalami penyegaran pada penghujung tahun 1970an dengan munculnya mazhab Cina. Mazhab ini hadir dengan paradigma baru yang berusaha mendislokasi pusat sastra bandingan dari Eropa kepada kesejajaran akan penerimaan dan pengakuan variasi-variasi di dalam menempatkan keliyanan dalam dialog antara Barat dan Timur.

Sementara itu, dunia digital telah mempengaruhi dan merombak batas-batas tradisional yang berkenaan dengan sastra, kepengarangan, konstruk baru akan identitas dan budaya, media dan pengalaman baru di dalam mengekspresikan dan meresepsi karya sastra dan produk budaya lainnya (Romero López, 2009; Ty, 2018). Era digital menghadirkan perspektif kosmopolitanisme dan ruang interaksi sosial yang berbeda dibandingkan dengan sebelumnya yang mempengaruhi ruang lingkup sastra bandingan (Boruszko, 2013), budaya transmedia, dan redefinisi lintas budaya dalam era konvergensi budaya di lingkungan digital (Baetens \& Sánchez-Mesa, 2015). Dalam keadaan inilah kemudian kajian intermedialitas menjadi ranah baru yang ramai dikaji di dalam sastra bandingan. Melihat dinamika sastra bandingan dengan isu-isu terkininya, sastra bandingan masih jauh dari mati dan justru terlihat akan terus berkembang.

\section{DAFTAR PUSTAKA}

Aaron, L. (2008). Writing a literature review article. Radiologic Technology, 80(2), $185-186$.

Retrieved

from http://www.radiologictechnology.org/content/80/2/185.full

Anderson, W. (1971). Matthew Arnold and the Grounds of Comparatism. Comparative Literature Studies, 8(4), 287-302. Retrieved from http://www.jstor.org/stable/40467974

Andersson, B., Beveridge, A., \& Singh, K. (2007). Literature review: Academic tip sheet (ed. Bennett, T). Perth, Western Australia: Edith Cowan University.

Baetens, J., \& Sánchez-Mesa, D. (2015). Literature in the expanded field: intermediality at the crossroads of literary theory and comparative literature. Interfaces. Image Texte Language, (36), 289-304. https://doi.org/10.4000/interfaces.245

Bassnett, S. (1993). Comparative literature: a critical introduction. Oxford, UK \& Cambridge, USA: Blackwell Publishers.

Bassnett, S. (2007). Influence and intertextuality: A reappraisal. Forum for Modern Language Studies, 43(2), 134-146. https://doi.org/10.1093/fmls/cqm004

Beecroft, A. (2013). Greek, Latin, and the origins of "world literature". CLCWeb: Comparative Literature and Culture, 15(5), 1-9. https://doi.org/10.7771/14814374.2334

Bermann, S. (2009). Working in the and zone: Comparative literature and 
translation. Comparative Literature, 61(4), 432-446. Retrieved from http://www.jstor.org/stable/40600339

Bernheimer, C. (1995). Comparative literature in the age of multiculturalism. Baltimore: Johns Hopkins University Press.

Blanariu, N. (2015). Alternative insights into comparative literature: interdisciplinary, intercultural, intersemiotic: dancing ekphrasis and transmedial narrative. In A. L. Varela \& A. Sukla (Eds), The ekphrastic turn: inter-art dialogues (pp. 130-167). Champaign, Illinois: Common Ground Publishing.

Bolderston, A. (2008). Writing an effective literature review. Journal of Medical Imaging and Radiation Sciences, 39(2), 86-92. https://doi.org/10.1016/j.jmir.2008.04.009

Boldor, A. (2003). Perspectives on comparative literature. The Interdepartmental Program in Comparative Literature, Graduate Faculty of the Louisiana State University and Agricultural and Mechanical College.

Boruszko, G. (2013). New technologies and teaching comparative literature. CLCWeb: Comparative Literature and Culture, 15(6), 1-9.

Brown, C. (2013). What is 'Comparative'Literature? Comparative Critical Studies, 10(1), 67-88. https://doi.org/10.3366/ccs.2013.0077

Cao, S. (2007). The Construction of a new paradigm of comparative literature studies. Comparative Literature: East \& West, 8(1), 31-56. https://doi.org/10.1080/25723618.2007.12015630

Claudon, F. (2018). Ampère and his "promenades" in Rome. Revue de Littérature Comparée, 367(3), 259-277. https://doi.org/10.3917/rlc.367.0259

D'haen, T. (2013). The Routledge Concise History of World Literature. London \& New York: Taylor \& Francis.

Damono, S. D. (2005). Pegangan penelitian sastra bandingan. Jakarta: Departemen Pendidikan Nasional, Pusat Bahasa.

Damono, S. D. (2009). Sastra bandingan. Jakarta: Editum.

Domínguez, C., Saussy, H., \& Villanueva, D. (2014). Introducing comparative literature: New trends and applications. London: Routledge.

Edmond, J. (2016). No discipline: An introduction to "The indiscipline of comparison". Comparative Literature Studies, 53(4), 647-659. https://doi.org/10.5325/complitstudies.53.4.0647

Endraswara, S. (2011). Metodologi Penelitian Sastra Bandingan. Jakarta: Bukupop.

Endraswara, S. (2013). Metodologi Penelitian Sastra. Yogyakarta: CAPS.

Franco, B. (2018). Comparative literature and world literature from goethe to globalization. In W. Fang (Ed), Tensions in world literature: between the local and the universal (pp. 65-76). Singapore: Palgrave Macmillan.

Fusco, S. (2006). The ironies of comparison: Comparative literature and the reproduction of cultural difference between East and West. TRANS- [En Ligne], 2. https://doi.org/https://doi.org/10.4000/trans.167

Gaither, M. (1961). Literature and the arts. In H. Frenz \& N. P. Stallknecht (Eds), Comparative Literature: Method and Perspective (pp. 153-170). Carbondale, IL: Southern Illinois University Press.

Hart, J. (2006). The futures of comparative literature: North America and beyond. Revue de Littérature Comparée, (1), 5-21.

Honko, L. (1986). Types of Comparison and Forms of Variation. Journal of Folklore Research,

$$
23(2 / 3)
$$

105-124.

Retrieved

from 
http://www.jstor.org/stable/3814443

Jay, P. (2014). State of the Discipline: Comparative Literature and Transdisciplinarity. Inquire: Journal of Comparative Literature, 3(2).

Jesson, J., \& Lacey, F. (2006). How to do (or not to do) a critical literature review. Pharmacy Education, 6(2), 139-148.

Lefevere, A. (1995). Introduction: Comparative literature and translation. Comparative Literature, 47(1), 1-10.

Lin, H., \& Huang, D. (2015). About the Chinese school of comparative literature. CLCWeb: Comparative Literature and Culture, 17(1), 1-8.

Lu, J. (2017). Reconsiderations on the Crises of Comparative Literature Study. CLCWeb: Comparative Literature and Culture, 19(5), 7.

Propp, V. I. A., Pírková-Jakobsonová, S., Wagner, L. A., \& Dundes, A. (1968). Morphology of the Folktale. Austin: University of Texas Press.

Rajewsky, I. (2005). Intermediality, intertextuality, and remediation: A literary perspective on intermediality. Intermédialités: Histoire et Théorie Des Arts, Des Lettres et Des Techniques/Intermediality: History and Theory of the Arts, Literature and Technologies, (6), 43-64.

Romero López, D. (2009). Cyberliteratures: a global perspective. Neohelicon, 36(2), 435-437. https://doi.org/10.1007/s11059-009-0012-6

Şahin, E. (2015). On Comparative Literature. International Joumal of Literature and Arts, 4(1-1), 5-12. https://doi.org/10.11648/j.ijla.s.2016040101.12

Saussy, H. (2006). Comparative literature in an age of globalization. Baltimore: Johns Hopkins University Press.

Saussy, H. (2011). The dimensionality of world literature. Neohelicon, 38(2), 289-294. https://doi.org/10.1007/s11059-011-0097-6

Teeuw, A. (1984). Sastra dan Ilmu Sastra: Pengantar Teori Sastra. Jakarta: Pustaka Jaya.

Tötösy de Zepetnek, S. (1998). Comparative Literature: Theory, Method, Application. Amsterdam, Atlanta: Rodopi.

Tötösy de Zepetnek, S. (1999). From comparative literature today toward comparative cultural studies. CLCWeb: Comparative Literature and Culture, 1(3), $1-15$.

Tötösy de Zepetnek, S. (2017). About the Situation of the Discipline of Comparative Literature and Neighboring Fields in the Humanities Today. Comparative Literature: East \& West, 1(2), 176-203.

Ty, E. (2018). Teaching Literatures in the Age of Digital Media. Canadian Review of Comparative Literature/Revue Canadienne de Littérature Comparée, 45(2), 213-221.

Wang, N. (2010). The Crisis of Comparative Literature and the Rise of World Literature. Comparative Literature: East \& West, 12(1), 28-32.

Wee, B. Van, \& Banister, D. (2016). How to write a literature review paper? Transport Reviews, 36(2), 278-288.

Weisstein, U. (1984). D'où venons nous? Que sommes-nous? Où allons-nous? The Permanent Crisis of Comparative Literature. Canadian Review of Comparative Literature/Revue Canadienne de Littérature Comparée, 167-192.

Wellek, R. (1970). General, Comparative, and National Literature. In Theory of Literature (pp. 46-53). New York: Harcourt, Brace \& World.

Wellek, R. (2009). The Crisis of Comparative Literature. In D. Damrosch, N. Melas, \& M. Buthelezi (Eds), The Princeton sourcebook in comparative literature: from the 
European Enlightenment to the global present (pp. 161-172). Princeton: Princeton University Press.

Wellek, R., \& Warren, A. (1993). Teori Kesusastraan (terj. Melani Budianta). Jakarta: Gramedia Pustaka Utama.

Wolf, W. (2011). (Inter) mediality and the Study of Literature. CLCWeb: Comparative Literature and Culture, 13(3), 1-9.

Zamora, L. P. (2004). Comparative Literature in an Age of "Globalization." Comparative Cultural Studies and Latin America, 4(3), 1-8. 